\title{
HUBUNGAN DUKUNGAN KELUARGA DAN PERAN KADER DENGAN PEMANFAATAN POSYANDU LANSIA DI WILAYAH KERJA PUSKESMAS KARANGNANDING KABUPATEN BENGKULU TENGAH
}

\author{
Giena, Vike Pebri ${ }^{*}$, Pawiliyah $^{2}$, Efrianto, Erwin $^{3}$ \\ 1,2,3Program Studi Ilmu Keperawatan STIKES Tri Mandiri Sakti Bengkulu \\ *Korespondensi: vikepebrigiena@gmail.com
}

\begin{abstract}
Background: Population. To realize healthy and quality elderly, health promotion must be carried out as early as possible, one of them through the formation and development of elderly posyandu groups. Purpose: This study aims to study the relationship of family support and the role of health volunteer with the use of posyandu for the elderly in the working area of Karangnanding Health Center, Karang Tinggi District, Bengkulu Tengah Regency. Methods: This research uses analytic survey design with cross sectional approach. The population in the study were all elderly people who participated in the Posyandu for the elderly in the working area of Karangnanding Health Center as many as 53 people. Sampling in this study using a total sampling technique. Data collection in this study uses primary and secondary data. Data analysis was performed univariately and bivariately. Results: The results obtained: (1) There is a relationship of family support with the use of posyandu for the elderly in the working area of Karang Nanding Health Center, with a moderate relationship category; (2) There is a relationship between the role of health volunteer and the use of posyandu for the elderly in the working area of Karangnanding Health Center, with the category of moderate relationship; (3) There is a relationship between the role of health volunteer and family support with the use of posyandu for the elderly in the working area of Karang Nanding Health Center, with a very close relationship category. Conclusion: The role of health volunteer and family support are factors related to the utilization of posyandu for the elderly. With the support from their families, the elderly tend to be more active in participating in posyandu activities for the elderly.
\end{abstract}

Keywords: Health volunter role; Family support; Posyandu elderly

\begin{abstract}
ABSTRAK
Latar Belakang: Indonesia termasuk negara yang akan masuk ke penduduk struktur tua dengan persentase penduduk lansia mencapai 7,6\% dari total penduduk. Untuk mewujudkan lansia sehat dan berkualitas, harus dilakukan pembinaan kesehatan sedini mungkin salah satu melalui pembentukan dan pembinaan kelompok posyandu lansia. Tujuan: Penelitian ini bertujuan untuk mempelajari hubungan dukungan keluarga dan peran kader dengan pemanfaatan posyandu lansia lansia di wilayah kerja Puskesmas Karangnanding Kecamatan Karang Tinggi Kabupaten Bengkulu Tengah. Metode: Penelitian ini menggunakan desain
\end{abstract}


survey analitik dengan pendekatan cross sectional. Populasi dalam penelitian adalah seluruh lansia yang mengikuti posyandu lansia di wilayah kerja wilayah kerja Puskesmas Karangnanding sebanyak 53 orang. Pengambilan sampel dalam penelitian ini menggunakan teknik total sampling. Pengumpulan data dalam penelitian ini menggunakan data primer dan sekunder. Analisis data dilakukan secara univariat dan bivariat. Hasil: Hasil penelitian didapatkan: Ada hubungan dukungan keluarga dengan pemanfaatan posyandu lansia di wilayah kerja Puskesmas Karang Nanding, dengan kategori hubungan sedang; Ada hubungan peran kader dengan pemanfaatan posyandu lansia lansia di wilayah kerja Puskesmas Karangnanding, dengan kategori hubungan sedang; Ada hubungan kategori peran kader sedang dan dukungan keluarga dengan pemanfaatan posyandu lansia lansia di wilayah kerja Puskesmas Karang Nanding, dengan kategori hubungan sangat erat. Simpulan: Peran Kader dan Dukungan keluarga adalah faktor-faktor yang berhubungan dengan pemanfaatan posyandu lansia. Dengan dukungan dari keluarga para lansia cenderung lebih aktif dalam mengikuti kegiatan posyandu lansia.

Kata Kunci: Peran kader; Dukungan keluarga; Posyandu lansia

\section{PENDAHULUAN}

Peningkatan usia harapan hidup merupakan salah satu indikasi kemajuan pembangunan kesehatan menuju Indonesia sehat. Secara global pada tahun 2013 proporsi dari populasi penduduk berusia lebih dari 60 tahun adalah 11,7\% dari total populasi di dunia. Data WHO menunjukan pada tahun 2000 usia harapan hidup orang didunia adalah 66 tahun, pada tahun 2012 naik menjadi 70 tahun dan pada tahun 2013 menjadi 71 tahun. Data WHO pada tahun 2009 menunjukan lansia berjumlah 7,49\% dari total populasi, tahun 2011 menjadi 7,69\% dan pada tahun 2013 didapatkan proporsi lansia sebesar 8,1\% dari total populasi (Sagitta, 2015).

Indonesia termasuk negara yang akan masuk ke penduduk struktur tua, karena persentase penduduk lanjut usia (lansia) yang telah mencapai 7,6\% dari total penduduk dan diproyeksikan akan terus meningkat pada tahun 2020-2035 seiring dengan Usia Harapan Hidup (UHH) Indonesia yang diproyeksikan akan terus meningkat dari 69,8 tahun (2010) menjadi 72,4 pada tahun 2035 (Kemenkes RI, 2018).

Pada lanjut usia telah terjadi kemunduran fisik pada organ tubuh. Ada beberapa hal yang perlu diperhatikan agar tetap sehat di usia lanjut yaitu dengan memperhatikan faktor gizi dan olahraga. Dengan semakin meningkatnya usia, maka sudah jelas kesegaran jasmani akan turun. Penurunan kemampuan akan 
semakin terlihat setelah usia 40 Tahun, sehingga saat lanjut usia, kemampuan akan turun antara 30-50 \% (Maryam, 2011)

Untuk mewujudkan lansia sehat dan berkualitas, harus dilakukan pembinaan kesehatan sedini mungkin dan selama siklus hidup manusia mulai dari janin sampai memasuki masa lansia dengan meminimalkan faktor risiko yang harus dihindari dan memaksimalkan faktor protektif yang dapat melindungi dan meningkatkan status kesehatan. Hal ini sejalan dengan kebijakan Kementerian Kesehatan yang menggalakkan Gerakan Masyarakat Hidup Sehat (GERMAS) untuk dilakukan oleh setiap individu, keluarga, dan masyarakat (Kemenkes RI, 2018)

Salah satu upaya untuk memberdayakan lanjut usia di masyarakat adalah melalui pembentukan dan pembinaan kelompok lansia di beberapa daerah disebut dengan Kelompok Usia Lanjut (Poksila), Pos Pelayanan Terpadu Lanjut Usia (Posyandu Lansia) atau Pos Pembinaan Terpadu Lanjut Usia (Posbindu Lansia) (Kemenkes RI, 2018)

Kegiatan posyandu lansia yang berjalan dengan baik akan memberi kemudahan bagi lansia dalam mendapatkan pelayanan kesehatan dasar, sehingga kualitas hidup masyarakat di usia lanjut tetap terjaga dengan baik dan optimal. Berbagai kegiatan dan program posyandu lansia tersebut sangat baik dan banyak memberikan manfaat bagi para orang tua di wilayahnya. Seharusnya para lansia berupaya memanfaatkan adanya posyandu tersebut sebaik mungkin agar kesehatan para lansia dapat terpelihara dan terpantau secara optimal (Sulistyorini, 2010)

Fenomena di lapangan menunjukkan fakta yang berbeda, pemanfaatan posyandu lansia sangat rendah. Hasil penelitian oleh Aminah (2012) di Posyandu Lansia Di Kelurahan Kali Balau Kencana Kecamatan Sukabumi Kota Bandar Lampung Tahun 2012, dari total lansia yang terdaftar sebanyak 52 lansia, rata-rata kehadiran tiap bulan sebanyak 9 orang lansia atau 36,5\%. Data tersebut juga mempunyai arti bahwa rata-rata tiap bulan jumlah kunjungan lansia ke posyandu kurang 50\% dari total lansia yang terdaftar di poslan

Terdapat beberapa faktor yang mempengaruhi keikutserta-an lansia dalam kegiatan posyandu lansia, diantaranya adalah dukungan keluarga dan peran kader. Peranan keluarga dalam perawatan lansia, keluarga merupakan support system utama bagi lansia dalam mempertahankan kesehataannya. Lansia, mempertahankan 
dan meningkatkan status mental, mengantisipasi perubahan sosial ekonomi, serta memberikan motivasi kebutuhan spiritual bagi lansia. Keluarga yang mempunyai lansia, perlu meningkatkan kepedulian dan peranan nya dalam melayani mereka agar lansia bisa nyaman dan hidup bahagia. Peran keluarga dalam pembinaan lansia berupa memenuhi kebutuhan ekonomi, psikososisl dan kesehataan fisik, nutrisi makanan serta berupaya mendorong lansia agar tepat berprilaku hidup sehat sehingga tercapai kualitas hidup lansia yang optimal (Maryam, 2011).

Selain itu, peran kader juga sangat penting pada kegiatan posyandu lansia untuk mencapai kinerja yang optimal. Keaktifan kader adalah tindakan nyata yang dilakukan oleh kader posyandu baik kegiatan sebelum posyandu, selama kegiatan posyandu maupun setelah kegiatan posyandu. Peran kader dalam pelayanan posyandu lansia yaitu melakukan pendaftaran lansia, menimbang lansia, mencatat dalam Kartu Menuju Sehat (KMS), membantu pemeriksaan laboratotium, melakukan penyuluhan serta membuat laporan setelah pelayanan posyandu selesai (Ughniyatul, 2015)

Menurut penelitian Nilasari (2012), tentang hubungan dukungan keluarga dan peran kader dengan keikutsertaan lansia mengikuti kegiatan posyandu lansia di posyandu Mawar Desa Tri Rahayu Kecamatan Negeri Katon Kabupaten Pesawaran 2012, disimpulkan bahwa terdapat hubungan yang signifikan antara dukungan keluarga dan peran kader dengan keikutsertaan lansia mengikuti kegiatan posyandu lansia

Menurut Profil Kesehatan Provinsi Bengkulu didapatkan pada tahun 2017 jumlah lansiaberusia $\geq 60$ tahun sebanyak 133.074 orang dengan lansia yang mengikuti posyandu lansia sebanyak 31.613 orang (24\%). Dengan jumlah keikutsertaan terendah berada pada Kabupaten Kaur 2\%, diikuti Kabupaten Bengkulu Selatan 5\% dan Kabupaten lebong 7\%. Sedangkan Kabupaten Bengkulu Tengah dengan jumlah keikutsertaan lansia pada posyandu lasia sebanyak $27 \%$

Berdasarkan data medical record Puskesmas Karangnanding didapatkan pada tahun 2017 jumlah lansia berusia $\geq 60$ tahun sebanyak 300 orang dengan keikutsertaan pada kegiatan posyandu lansia sebanyak 37,7\%. Pada tahun 2018 jumlah lansia berusia $\geq 60$ tahun sebanyak 325 orang dengan keikutsertaan pada kegiatan posyandu lansia sebanyak 39,2\%. Kondisi ini menunjukkan kurangnya 
minat lansia untuk memanfaatkan posyandu lansia untuk mendapatkan pelayanan kesehatan, padahal target nasional kunjungan lansia sebesar $70 \%$.

Berdasarkan uraian pada latar belakang, maka rumusan masalah dalam penelitian ini "adakah hubungan dukungan keluarga dan peran kader dengan pemanfaatan posyandu lansia lansia di wilayah kerja Puskesmas Karangnanding Kecamatan Karang Tinggi Kabupaten Bengkulu Tengah?”

\section{TUJUAN}

Tujuan dari penelitian ini adalah unutk melihat hubungan dukungan keluarga dan peran kader dengan pemanfaatan posyandu lansia di wilayah kerja Puskesmas Karangnanding Kecamatan Karang Tinggi Bengkulu Tengah.

\section{METODE}

Penelitian ini mengguna-kan desain survey analitik dengan pendekatan cross sectional. Populasi dalam penelitian adalah seluruh lansia yang mengikuti posyandu lansia di wilayah kerja wilayah kerja Puskesmas Karangnanding sebanyak 53 orang. Pengambilan sampel dalam penelitian ini menggunakan teknik total sampling. Pengumpulan data dalam penelitian ini menggunakan data primer dan sekunder. Analisis data dilakukan secara univariat dan bivariat. Kuesioner dukungan keluarga terdiri dari 10 pertanyaan positif dan kuesioner peran kader terdiri dari 10 pertanyaan positif dengan 4 (empat) pilihan jawaban yaitu; Selalu diberikan skor 4, Sering diberikan skor 3, Kadang-kadang diberikan skor 2 dan Tidak Pernah diberikan skor 1 (Nasution, 2013).

\section{HASIL}

\section{Analisis Univariat}

Analisis univariat di-lakukan untuk memperoleh gambaran tentang variabel independen (dukungan keluarga dan peran kader) dan variabel dependen (pemanfaatan posyandu lansia). Didapatkan hasil sebagai berikut: 
Tabel 1. Distribusi Frekuensi Pemanfaatan Posyandu Lansia di Wilayah Kerja Puskesmas Karang Nanding

\begin{tabular}{cccc}
\hline No & $\begin{array}{c}\text { Pemanfaatan Posyandu } \\
\text { Lansia Lansia }\end{array}$ & Frekuensi & Persentase (\%) \\
\hline 1 & Teratur & 15 & 28,3 \\
2 & Tidak Teratur & 38 & 71,7 \\
\hline & Jumlah & 53 & 100,0 \\
\hline
\end{tabular}

Berdasarkan tabel frekuensi pemanfaatan posyandu lansia diatas, tampak bahwa dari 53 orang lansia terdapat 15 orang $(28,3 \%)$ dengan pemanfaatan posyandu teratur dan 38 orang $(71,7)$ dengan pemanfaatan posyandu tidak teratur.

Gambaran dukungan keluarga di wilayah kerja Puskesmas Karangnanding Kecamatan Karang Tinggi Kabupaten Bengkulu Tengah

Tabel 2. Distribusi Frekuensi Dukungan Keluarga Di Wilayah Kerja Puskesmas Karang Nanding

\begin{tabular}{|c|c|c|c|}
\hline No & Dukungan Keluarga & Frekuensi & Persentase $(\%)$ \\
\hline 1 & Baik & 16 & 30,2 \\
\hline 2 & Sedang & 24 & 45,3 \\
\hline 3 & Kurang & 13 & 24,5 \\
\hline \multicolumn{2}{|r|}{ Jumlah } & 53 & 100,0 \\
\hline
\end{tabular}

Berdasarkan tabel frekuensi dukungan keluarga diatas, tampak bahwa dari 53 orang lansia terdapat 16 orang (30,2\%) dengan dukungan keluarga baik, 24 orang $(45,3 \%)$ dengan dukungan keluarga sedang dan 13 orang $(24,5 \%)$ dengan dukungan keluarga kurang.

Tabel 3. Distribusi Frekuensi Peran Kader Di Wilayah Kerja Puskesmas Karang Nanding

\begin{tabular}{cccc}
\hline No & Peran Kader & Frekuensi & Persentase (\%) \\
\hline 1 & Baik & 19 & 35,8 \\
2 & Sedang & 13 & 24,5 \\
3 & Kurang & 21 & 39,6 \\
\hline
\end{tabular}

Berdasarkan tabel frekuensi peran kader diatas, tampak bahwa dari 53 orang lansia terdapat 19 orang $(35,8 \%)$ dengan peran kader baik, 13 orang $(24,5 \%)$ dengan peran kader sedang dan 21 orang $(39,6 \%)$ dengan peran kader kurang. 


\section{Analisis Bivariat}

Analisis bivariat digunakan untuk melihat hubungan antara variabel independen dan variabel dependen dengan hasil sebagai berikut:

Tabel 4. Hasil Uji Korelasi Pearson Chi-Square

\begin{tabular}{|c|c|c|c|c|c|c|c|}
\hline \multirow{2}{*}{ No } & \multirow{2}{*}{$\begin{array}{c}\text { Dukungan } \\
\text { Keluarga }\end{array}$} & \multicolumn{2}{|c|}{$\begin{array}{c}\text { Pemanfaatan Posyandu } \\
\text { Lansia }\end{array}$} & \multirow[t]{2}{*}{ Total } & \multirow{2}{*}{$x^{2}$} & \multirow{2}{*}{$P$} & \multirow{2}{*}{$\mathrm{C}$} \\
\hline & & Teratur & Tidak Teratur & & & & \\
\hline 1 & Baik & 8 & 8 & 16 & & & \\
\hline 2 & Sedang & 6 & 18 & 24 & 6,562 & 0,038 & 0,332 \\
\hline \multirow[t]{2}{*}{3} & Kurang & 1 & 12 & 13 & & & \\
\hline & Jumlah & 15 & 38 & 53 & & & \\
\hline
\end{tabular}

Berdasarkan tabulasi silang antara dukungan keluarga dengan pemanfaatan posyandu lansia diatas menunjukkan dari 16 orang lansia dengan dukungan keluarga baik terdapat 8 orang dengan pemanfaatan posyandu teratur dan 8 orang tidak teratur, dari 24 orang lansia dengan dukungan keluarga sedang terdapat 6 orang dengan pemanfaatan posyandu teratur dan 18 orang tidak teratur dan dari 13 orang lansia dengan dukungan keluarga kurang terdapat 1 orang dengan pemanfaatan posyandu teratur dan 12 orang tidak teratur.

Hasil uji Pearson Chi-Square didapat nilai $\chi^{2}=6,562$ dengan $\mathrm{p}$-value $=$ $0,038<0,05$ berarti signifikan, maka Ho ditolak dan Ha diterima. Jadi ada hubungan dukungan keluarga dengan pemanfaatan posyandu lansia lansia di wilayah kerja Puskesmas Karang Nanding Kecamatan Karang Tinggi Kabupaten Bengkulu Tengah.

Hasil uji Contingency Coefficient didapat nilai $\mathrm{C}=0,332$ dengan $\mathrm{p}$ value $=0,005<0,05$ berarti signifikan, nilai $\mathrm{C}$ tersebut dibandingkan dengan nilai $\mathrm{C}_{\max }=0,707$ (nilai $m$ adalah nilai terendah dari baris atau kolom). Jadi nilai $\frac{C}{C_{\max }}$ $=\frac{0,332}{0,707}=0,469$, karena nilai ini terletak dalam interval 0,40-0,60 maka kategori hubungan sedang. 
Tabel 5. Hasil Uji Korelasi Pearson Chi-Square

\begin{tabular}{|c|c|c|c|c|c|c|c|}
\hline \multirow{3}{*}{ No } & \multirow{3}{*}{ Peran Kader } & \multirow{2}{*}{\multicolumn{2}{|c|}{$\begin{array}{c}\text { Pemanfaatan Posyandu } \\
\text { Lansia }\end{array}$}} & \multirow{3}{*}{ Total } & \multirow{3}{*}{$\chi^{2}$} & \multirow{3}{*}{$\mathrm{P}$} & \multirow{3}{*}{$\mathrm{C}$} \\
\hline & & & & & & & \\
\hline & & Teratur & Tidak Teratur & & & & \\
\hline 1 & Baik & 9 & 10 & 19 & & & \\
\hline 2 & Sedang & 4 & 9 & 13 & 7,092 & 0,029 & 0,344 \\
\hline \multirow[t]{2}{*}{3} & Kurang & 2 & 19 & 21 & & & \\
\hline & Jumlah & 15 & 38 & 53 & & & \\
\hline
\end{tabular}

Berdasarkan tabulasi silang antara peran kader dengan pemanfaatan posyandu lansia diatas menunjukkan dari 19 orang peran kader baik terdapat 9 orang pemanfaatan posyandu teratur dan 10 orang tidak teratur, dari 13 orang peran kader sedang terdapat 4 orang pemanfaatan posyanru teratur Dan 9 orang tidak teratur, dan dari 21 orang peran kader kurang terdapat 2 orang pemanfaatan posyandu teratur dan 19 orang tidak teratur.

Hasil uji Pearson Chi-Square didapat nilai $\chi^{2}=7,092$ dengan $\mathrm{p}$-value $=$ $0,029<0,05$ berarti signifikan, maka Ho ditolak dan Ha diterima. jadi Ada hubungan peran kader dengan pemanfaatan posyandu lansia lansia di wilayah kerja Puskesmas Karangnanding Kecamatan Karang Tinggi Kabupaten Bengkulu Tengah

Hasil uji Contingency Coefficient didapat nilai $\mathrm{C}=0,344$ dengan $\mathrm{p}$-value $=$ $0,005<0,05$ berarti signifikan, nilai $\mathrm{C}$ tersebut dibandingkan dengan nilai $\mathrm{C}_{\max }=$ 0,707 (nilai $m$ adalah nilai terendah dari baris atau kolom). Jadi nilai $\frac{C}{C_{\max }}=\frac{0,344}{0,707}$ $=0,486$, karena nilai ini terletak dalam interval 0,40-0,60 maka kategori hubunangan sedang. 
Tabel 6. Hasil Uji Korelasi Pearson Chi-Square

\begin{tabular}{|c|c|c|c|c|c|c|c|c|}
\hline \multirow{2}{*}{ No } & \multirow{2}{*}{ Peran Kader } & \multirow{2}{*}{$\begin{array}{c}\text { Dukungan } \\
\text { Keluarga }\end{array}$} & \multicolumn{2}{|c|}{$\begin{array}{c}\text { Pemanfaatan } \\
\text { Posyandu }\end{array}$} & \multirow{2}{*}{ Total } & \multirow{2}{*}{$\chi^{2}$} & \multirow{2}{*}{$\mathrm{P}$} & \multirow{2}{*}{$\mathrm{C}$} \\
\hline & & & Teratur & $\begin{array}{c}\text { Tidak } \\
\text { Teratur }\end{array}$ & & & & \\
\hline \multirow[t]{4}{*}{1} & \multirow[t]{4}{*}{ Baik } & Baik & 3 & 4 & 7 & \multirow{4}{*}{1,184} & \multirow{4}{*}{0,553} & \multirow{4}{*}{-} \\
\hline & & Sedang & 5 & 6 & 11 & & & \\
\hline & & Kurang & 1 & 0 & 1 & & & \\
\hline & & Jumlah & 9 & 10 & 19 & & & \\
\hline \multirow[t]{4}{*}{2} & \multirow[t]{4}{*}{ Sedang } & Baik & 4 & 2 & 6 & \multirow{4}{*}{6,741} & \multirow{4}{*}{0,034} & \multirow{4}{*}{0,584} \\
\hline & & Sedang & 0 & 2 & 2 & & & \\
\hline & & Kurang & 0 & 5 & 5 & & & \\
\hline & & Jumlah & 4 & 9 & 13 & & & \\
\hline \multirow[t]{4}{*}{3} & \multirow[t]{4}{*}{ Kurang } & Baik & 1 & 2 & 3 & \multirow{4}{*}{2,713} & \multirow{4}{*}{0,258} & \multirow{4}{*}{-} \\
\hline & & Sedang & 1 & 10 & 11 & & & \\
\hline & & Kurang & 0 & 7 & 7 & & & \\
\hline & & Jumlah & 2 & 19 & 21 & & & \\
\hline
\end{tabular}

Berdasarkan hasil penelitian didapatkan bahwa dari 19 orang dengan peran kader baik terdapat 7 orang dengan dukungan keluarga baik, 11 orang dengan dukungan keluarga sedang dan 1 orang dengan dukungan keluarga kurang. Dari 7 orang dengan dukungan keluarga baik terdapat 3 orang dengan pemanfaatan posyandu teratur dan 4 orang tidak teratur.

Dari 11 orang dengan dukungan keluarga sedang terdapat 5 orang dengan pemanfaatan posyandu teratur dan 6 orang tidak teratur. Dari 1 orang dengan dukungan keluarga kurang terdapat 1 orang dengan pemanfaatan posyandu teratur.

Dari 13 orang dengan peran kader sedang terdapat 6 orang dengan dukungan keluarga baik, 2 orang dengan dukungan keluarga sedang dan 5 orang dengan dukungan keluarga kurang. Dari 6 orang dengan dukungan keluarga baik terdapat 4 orang dengan pemanfaatan posyandu teratur dan 2 orang tidak teratur. Dari 2 orang dengan dukungan keluarga sedang terdapat 2 orang dengan pemanfaatan posyandu tidak teratur. Dari 5 orang dengan dukungan keluarga kurang terdapat 5 orang dengan pemanfaatan posyandu tidak teratur.

Dari 21 orang dengan peran kader kurang terdapat 3 orang dengan dukungan keluarga baik, 11 orang dengan dukungan keluarga sedang dan 7 orang dengan 
dukungan keluarga kurang. Dari 3 orang dengan dukungan keluarga baik terdapat 1 orang dengan pemanfaatan posyandu teratur dan 2 orang tidak teratur. Dari 11 orang dengan dukungan keluarga sedang terdapat 1 orang dengan pemanfaatan posyandu teratur dan 10 orang tidak teratur. Dari 7 orang dengan dukungan keluarga kurang terdapat 7 orang dengan pemanfaatan posyandu tidak teratur.

Hasil uji Pearson Chi-Square didapat pada kategori peran kader sedang nilai $\chi^{2}=6,741$ dengan $\mathrm{p}$-value $=0,034<0,05$ berarti signifikan, maka Ho ditolak dan Ha diterima. jadi Ada hubungan kategori peran kader sedang dan dukungan keluarga dengan pemanfaatan posyandu lansia lansia di wilayah kerja Puskesmas Karang Nanding Kecamatan Karang Tinggi Kabupaten Bengkulu Tengah. Sedangkan pada kategori peran kader baik dan kurang tidak terdapat hubungan yang signifikan.

Pada kategori peran kader sedang, keeratan hubungan antara dukungan keluarga dengan pemanfaatan posyandu menurut uji Contingency Coefficient didapat nilai $\mathrm{C}=0,584$ dengan $\mathrm{p}$-value $=0,034<0,05$ berarti signifikan, nilai $\mathrm{C}$ tersebut dibandingkan dengan nilai $\mathrm{C}_{\max }=0,707$ (nilai $m$ adalah nilai terendah dari

baris atau kolom). Jadi nilai $\frac{C}{C_{\max }}=\frac{0,584}{0,707}=0,826$, karena nilai ini terletak dalam interval 0,80 - 1,00 maka kategori hubungan sangat erat.

\section{PEMBAHASAN}

Berdasarkan hasil penelitian, tampak bahwa dari 53 orang lansia terdapat 15 orang $(28,3 \%)$ dengan pemanfaatan posyandu teratur dan 38 orang $(71,7)$ dengan pemanfaatan posyandu tidak teratur. Kondisi ini menujukkan bahwa sebagian besar lansia yang di wilayah kerja Puskesmas Karang Nanding dengan kunjungan posyandu lansia yang kurang teratur yaitu kunjungan $<8$ kali selama 1 tahun.

Sulistyorini (2010) mengatakan bahwa salah satu indikasi dalam pemanfaat posyandu lansia dikatakan baik dapat dilihat dari tingkat kepatuhan lansia untuk ikut dalam kegiatan posyandu lansia sehingga kesehatan lansia dapat terjaga dengan baik. Kepatuhan dapat dihubungkan dengan interaksi kompleks antara dukungan keluarga, pengalaman, dan nilai-nilai kepribadian professional kesehatan melakukan pengajaran dan kompleksitas program. Sedangkan bila frekuensi penimbangan sudah $\geq 8$ kali dalam kurun waktu satu tahun dianggap sudah teratur. 
Berdasarkan hasil penelitian tampak bahwa dari 53 orang lansia terdapat 16 orang $(30,2 \%)$ dengan dukungan keluarga baik, 24 orang $(45,3 \%)$ dengan dukungan keluarga sedang dan 13 orang (24,5\%) dengan dukungan keluarga kurang. Kondisi ini menunjukkan bahwa hampir sebagian lansia yang mengikuti kegiatan posyandu lansia dengan dukungan keluarga kategori sedang.

Nursalam (2013) mengatakan bahwa dukungan sosial sangat diperlukan oleh setiap individu di dalam setiap siklus kehidupan. Salah satu sumber dukungan sosial yang paling berperan penting dalam mempengaruhi seseorang dalam pelayanan kesehatan adalah keluarga. Dimana keluarga merupakan bagian terdekat dari lansia yang dapat memberikan dukungan emosional dan dukungan moral bagi lansia.

Berdasarkan hasil penelitian tampak bahwa dari 53 orang lansia terdapat 19 orang $(35,8 \%)$ dengan peran kader baik, 13 orang $(24,5 \%)$ dengan peran kader sedang dan 21 orang $(39,6 \%)$ dengan peran kader kurang. Hasil ini menunjukkan bahwa hampir sebagain lansia mengatakan bahwa peran kader terhadap pemanfaatan posyandu oleh lansia berada pada kategori kurang.

Sejalan dengan Margiyati (2010) bahwa kader bukanlah tenaga kesehatan profesional melainkan hanya membantu dalam pelayanan kesehatan, maka ada pembatasan kegiatan yang harus dilakukan. Upaya kesehatan yang dilakukan oleh kader dalam posyandu lansia mencakup kegiatan promosi dan pengisian pemantaun kesehatan pribadi dan senam lansia, mempengaruhi lansia terhadap kunjungan ke posyandu karena pelayanannya yang menyenangkan, ramah, dan memberikan informasi serta penyuluhan kesehatan yang jelas dan mudah dimengerti lansia, sehingga lansia lebih sadar untuk datang ke posyandu lansia.

Berdasarkan hasil penelitian didapatkan dari 16 orang lansia dengan dukungan keluarga baik terdapat 8 orang dengan pemanfaatan posyandu teratur dan 8 orang tidak teratur. Kondisi ini menunjukkan bahwa dukungan keluarga yang baik akan membantu lansia untuk aktif mengikuti kegiatan posyandu lansia. Namun dukungan keluarga saja tidak cukup bagi lansia dibuktikan terdapat 8 orang lansia yang tidak teratur mengikuti kegiatan posyandu walaupun dengan dukungan keluarga yang baik. Hasil penelitian menunjukkan lansia mengatakan mengikuti kegiatan posyadu jika beberapa hari terakhir mengalamai masalah kesehatan saja 
sehingga dapat mendapatkan pengobatan. Maka diperlukan motivasi dan persepsi dari lansia yang baik terhadap kegiatan posyandu lansia.

Dari 24 orang lansia dengan dukungan keluarga sedang terdapat 6 orang dengan pemanfaatan posyandu teratur dan 18 orang tidak teratur. Kondisi ini menunjukkan bahwa pada kategori dukungan keluarga sedang lebih banyak lansia tidak mengikuti kegiatan posyandu dengan teratur hal ini dikarenakan pada saat penelitian lansia mengatakan terkadang lupa dengan jadwal kegiatan, hal ini berhubungan dengan dukungan keluarga yang hanya sebatas kategori sedang. Dukungan keluarga yang hanya sebatas kategori sedang terkadang akan membuat keluarga lupa mengingatkan lansia tentang jadwal kegiatan. Untuk mengingat jadwal kegiatan tidak bisa hanya mengandalkan lansia saja karena pada lansia telah terjadi kemunduran fungsi salah satunya adalah pada fungsi kognitif untuk mengingat sesuatu atau yang sering kita sebut pikun. Dibuktikan dengan pada hasil penelitian bahwa usia lansia yang mengikuti posyandu lansia termuda adalah usia 60 tahun, usia tertua adalah 77 tahun dan rata-rata usia lansia adalah 68,3 tahun. Sehingga dengan usia kategori usia lanjut usia dan lanjut usia tua tersebut telah terjadi kemunduran pada fungsi organ maupun pada fungsi kognitif.

Dari 13 orang lansia dengan dukungan keluarga kurang terdapat 1 orang dengan pemanfaatan posyandu teratur, ini menunjukkan bahwa lansia dengan dukungan yang rendah juga dapat melakukan kunjungan posyandu dengan teratur yaitu pada Ny. R yang tercatat melakukan kunjungan posyandu sebanyak 9 kali selama 1 tahun terakhir. Hal ini terjadi karena menurut Ny. R berdasarkan kuesioner ia menyantakan peran kader dalam kategori baik pada Ny. R sehingga dengan dukungan kader yang, dia dapat selalu mengikuti kegiatan posyandu lansia, selain itu faktor lain adalah rumah $\mathrm{Ny}$. R berdekatan dengan tempat posyandu lansia.

Dari lansia dengan dukungan keluarga kurang terdapat 12 orang tidak teratur. Dukungan keluarga yang kurang akan mempengaruhi lansia untuk ikut dalam kegiatan posyandu lansia. Lansia membutuhkan keluarga untuk dapat menjaga kehatan tubuhnya, karena lansia sudah mempunya keterbatasan kemampuan untuk menjangkau tempat-tempat pelayanan kesehatan, keterbatasan dalam mengingat jadwal kegiatan serta keterbatasan melakukan aktifitas akibat penurunan metabolism dalam tubuh yang menyebabkan lansai mudah lelah dan menjadi malas 
untuk mengikuti kegiatan diluar rumahnya. Maka keluarga harus berperan aktif untuk membantu lansia dalam mendapatkan akses pelayanan kesehatan dengan segala keterbatasannya.

Hasil uji Pearson Chi-Square didapatkan ada hubungan dukungan keluarga dengan pemanfaatan posyandu lansia lansia di wilayah kerja Puskesmas Karang Nanding Kecamatan Karang Tinggi Kabupaten Bengkulu Tengah. Hal ini menunjukkan bahwa dukungan keluarga diperlukan oleh lansia dalam segala kegiatannya dalam mempertahankan kesehatannya seperti posyandu lansia. Sejalan dengan Maryam (2011) yang menyatakan bahwa peranan keluarga dalam perawatan lansia sebagai support system utama bagi lansia dalam mempertahankan kesehataannya lansia, mempertahankan dan meningkatkan status mental, mengantisipasi perubahan sosial ekonomi, serta memberikan motivasi kebutuhan spiritual bagi lansia.

Hasil uji Contingency Coefficient didapat kategori hubungan sedang. Hasil kategori hubungan sedang menunjukkan bahwa dukungan keluarga bukanlah meupakan faktor utama yang mendukung pemanfaatan posyandu pada lansia, hal ini karena masih terdapat faktor lain yang berhubungan dengan pemanfaatan posyandu lansia. Hasil temuan peneliti ini sejalan dengan penelitian menurut Darwis (2014) yang meneliti tentang faktor-faktor yang berhubungan dengan kunjungan lansia ke posyandu lansia di wilayah kerja Puskesmas Rapak Mahang Kabupaten Kutai Kertanegara. Didapatkan hasil bahwa terdapat hubungan antara motivasi lansia, peran kader, peran petugas dan persepsi lansia terhadap program pelayanan kesehatan dengan kunjungan lansia ke posyandu.

Berdasarkan hasil penelitian didapatkan bahwa dari 19 orang peran kader baik terdapat 9 orang pemanfaatan posyandu teratur. Hasil ini menunjukkan bahwa peran kader yang baik akan mendukung lansia dalam melakukan kunjungan posyandu dengan teratur karena ada system pengingat bagi lansia selain keluarga. Selain itu dari lansia dengan peran kader baik terdapat 10 orang tidak teratur. Kondisi ini menunjukkan bahwa peran kader yang baik tidak secara langsung membuat lansia teratur melakukan kunjungan posyandu. Hal ini disebabkan karena adanya faktor lain seperti 3 orang mengatakan kurang paham dengan kegiatan posyandu pengetahuan lansia yang kurang tentang pelayanan kesehatan seperti 
Dari 13 orang peran kader sedang terdapat 4 orang pemanfaatan posyandu teratur dan 9 orang tidak teratur. Hasil ini menunjukkan bahwa pada peran kader yang sedang kemungkinan lansia untuk berperan aktif dalam kegiatan posyandu rendah, karena peran kader dalam kegiatan posyandu hanya sebatas pembantu tenaga kesehatan dan bukan merupakan tenaga profesional, dan mengingat pendidikan kader rata-rata sebatas pendidikan mengah sehingga kader juga memiliki pemahan yang terbatas dalam menjelaskan tentang posyandu lansia sehingga akan mempengaruhi ketertarikan dan minat lansia pada kegiatan posyandu lansia.

Dari 21 orang peran kader kurang terdapat 2 orang pemanfaatan posyandu teratur. Hal ini dipengaruhi oleh faktor pendidikan dan pekerjaan lansia itu sendiri, seperti pada Tn. B dengan pendidikan menengah atau tamatan SMA, sehingga memiliki pemahaman dan persepri yang baik tentang program posyandu lansia. Selain itu pada Ny. Y yang merupakan pensiunan PNS. Lansia ynag bekerja akan mempengaruhi tingkat pengtahuan dan pemahaman lansia, karena dengan bekerja lansia akan sering berinteraksi dengan orang lain serta akan terjadi pertukaran informasi dan perubahan pola pikir kea rah yang lebih baik dibandingkan dengan lansia yang tidak bekerja.

Selain itu dari 21 orang peran kader kurang terdapat 19 orang tidak teratur. Hasil penelitian ini menunjukkan bahwa peran kader sangat dibutuhkan dalam kegiatan posyandu lansia terutama dalam hal promosi dan mengajak lansia untuk ikut aktif dalam kegiatan posyandu lansia. Hal ini ditunjukkan dari hasil penelitian bahwa hampir seluruh lansia yang menyatakan peran kader kurang akan berdampak pada ketidakteraturan lasia dalam mengikuti kegiatan posyandu lansia.

Hasil uji Pearson Chi-Square didapatkan hasil ada hubungan peran kader dengan pemanfaatan posyandu lansia lansia di wilayah kerja Puskesmas Karangnanding Kecamatan Karang Tinggi Kabupaten Bengkulu Tengah. Kondisi ini menunjukkan bahwa kader kesehatan mempunyai peran yang besar terhadap posyandu lansia. Kader kesehatan mempunyai peran yang besar dalam upaya meningkatkan kemampuan masyarakat menolong dirinya untuk mencapai derajat kesehatan yang optimal. Selain itu, kader turut ikut serta dalam membina masyarakat di bidang kesehatan melalui kegiatan yang dilakukan di posyandu. 
Hasil uji Contingency Coefficient didapat kategori hubunangan sedang. Kategori hubungan sedang menunjukkan bahwa masih terdapat faktor lain selain peran kader terhadap kunjungan lansia ke posyandu lansia. Hasil ini sejalan dengan penelitian menurut Melita (2018), faktor-faktor yang berhubungan dengan kunjungan lansia ke posbindu lansia di wilayah kerja Puskesmas Kelurahan Bintara Kota Bekasi. Didapatkan hasil bahwa faktor-faktor yang berhubungan adalah pengetahuan, dukungan keluarga, dukungan petugas kesehatan dan faktor kebutuhan terhadap kunjungan lansia ke posbindu lansia di wilayah kerja Puskesmas Kelurahan Bintara Kota Bekasi.

Berdasarkan hasil penelitian didapatkan bahwa dari 7 orang dengan peran kader baik disertai dengan dukungan keluarga baik terdapat 3 orang dengan pemanfaatan posyandu teratur dan 4 orang tidak teratur. Dari 11 orang dengan peran kader baik disertai dengan dukungan keluarga sedang terdapat 5 orang dengan pemanfaatan posyandu teratur dan 6 orang tidak teratur. Dari 1 orang dengan peran kader baik disertai dengan dukungan keluarga kurang terdapat 1 orang dengan pemanfaatan posyandu teratur Hasil ini menunjukkan bahwa walaupun lansia disetai dengan peran kader baik dan dukungan yang baik pula cenderung melakukan kunjungan yang tidak teratur pada posyandu lansia. Hal ini menunjukkan bahwa peran kader dan dukungan keluarga tidak sepenuhnya membuat lansia teratur melakukan kunjungan posyandu, karena dalam penelitian dari lansia yang tidak melakukan kunjungan dengan teratur dikarenakan terkadang lupa dengan jadwal kunjungan, adanya kekambuhan penyakit seperti rematik sehingga menghambat lansia untuk mengikuti kegiatan dan adanya faktor kesibukan sibuk diladang sehingga lansia tidak sempat mengikuti posyandu lansia.

Dari 6 orang dengan peran kader sedang disertai dukungan keluarga baik terdapat 4 orang dengan pemanfaatan posyandu teratur dan 2 orang tidak teratur. Dari 2 orang dengan peran kader sedang disertai dukungan keluarga sedang terdapat 2 orang dengan pemanfaatan posyandu tidak teratur. Dari 5 orang dengan peran kader sedang disertai dukungan keluarga kurang terdapat 5 orang dengan pemanfaatan posyandu tidak teratur. Hasil ini menunjukkan bahwa pada lansia dengan peran kader kurang dan disertai dukungan keluarga yang baik cenderung melakukan kunjungan posyandu dengan teratur dan pada lansia dengan dukungan 
keluarga sedang dan kurag cenderung melakukan kunjungan posyandu tidak teratur. Hal ini menunjukkan pentingnya dukungan keluarga pada keteraturan kunjungan posyandu lansia karena peran kader secara umum sebatas mengingatkan lansia untuk ikut posyandu sedangkan keluarga berperan penuh pada kegiatan lansia baik secara moril maupun materil seperti mengingatkan, mengantar, menemani selama kegiatan dan menjemput kembali lansia setelah kegiatan selesai.

Dari 3 orang dengan peran kader kurang disertai dukungan keluarga baik terdapat 1 orang dengan pemanfaatan posyandu teratur dan 2 orang tidak teratur. Dari 11 orang dengan peran kader kurang disertai dukungan keluarga sedang terdapat 1 orang dengan pemanfaatan posyandu teratur dan 10 orang tidak teratur. Dari 7 orang dengan peran kader kurang disertai dukungan keluarga terdapat 7 orang dengan pemanfaatan posyandu tidak teratur. Kondisi ini menunjukkan bahwa semakin buruk peran kader dan dukungan keluarga secara bersamaan akan membuat lansia semakin lalai dalam mengikuti kegiatan posyandu lansia karena kurang mendapatkan informasi baik dari kader maupun keluarga sehingga lansia kurang paham tetang kegiatan posyandu. Adapun lansia melakukan kunjungan posyandu sebagian besar mengatakan kurang tahu tentang kegiatan namun tetap ikut karena ingin mendapatkan pengobatan saja berhubung dengan keluhan penyakit yang dideritanya sehingga lansia berkunjung jika hanya ada keluhan terhadap penyakit saja dan tidak mengikuti kegiatan jika dirasa tidak ada keluhan terhadap penyakit yang dideritanya.

Hasil uji Pearson Chi-Square didapat ada hubungan kategori peran kader sedang dan dukungan keluarga dengan pemanfaatan posyandu lansia lansia di wilayah kerja Puskesmas Karang Nanding Kecamatan Karang Tinggi Kabupaten Bengkulu Tengah. Sedangkan pada kategori peran kader baik dan kurang tidak terdapat hubungan yang signifikan. Hasil ini sejalan dengan penelitian menurut Rahmawati (2017) yang meneliti tentang hubungan dukungan sosial keluarga dan kader dengan kunjungan lansia laki-laki ke posyandu lansia di wilayah kerja Puskesmas Klirong 1 Kabupaten Kebumen. Didapatkan hasil bahwa terdapat hubungan antara dukungan sosial keluarga dan kader dengan kunjungan lansia lakilaki ke posyandu lansia di wilayah kerja Puskesmas Klirong 1 Kabupaten Kebumen. 
Penelitian lain menurut Zakir (2014) yang meneliti tentang faktor-faktor yang behubungan dengan pemanfaatan Posyandu Lansia Kencana di Wilayah Kerja Puskesmas Sukabumi Bandar Lampung, disimpulkan bahwa terdapat hubungan yang signifikan antara peran kader dan dukungan keluarga dengan pemanfaatan Posyandu Lansia Kencana di Wilayah Kerja Puskesmas Sukabumi Bandar Lampung. Menurut Maryam (2011), dalam melakukan perawatan terhadap lansia, setiap anggota keluarga memiliki peranan yang sangat penting. Peranan keluarga antara lain menjaga dan merawat lansia, mepertahankan dan meningkatkan status mental, mengantisipasi perubahan sosial ekonomi, serta memberikan motivasi dan memfasilitasi kebutuhan spiritual bagi lansia..

Maka peneliti menyimpulkan bahwa kader dapat mempengaruhi semangat dan motivasi keluarga maupun lansia sendiri dengan dorongan dan manfaat yang disampaikan oleh kader. Maka dari itu peran kader meningkatkan dukungan kader dengan memberikan penyuluhan oleh petugas kesehatan kepada kader-kader posyandu agar memahami tujuan dari kegiatan posyandu lansia sehingga dapat mempengaruhi masyarakat lansia dan keluarga untuk lebih memperhatikan kesehatan tubuh lansia dengan mengikuti kegiatan posyandu lansia.

Berdasarkan hasil penelitian maka didapatkan hubungan yang signifikan antara dukungan keluarga dan peran kader dengan pemanfaatan posyandu lansia lansia di wilayah kerja Puskesmas Karang Nanding Kecamatan Karang Tinggi, maka diharapkan bagi Puskesmas Karang Nanding untuk meningkatkan pelayanan kesehatan bagi lansia khususnya posyandu lansia dengan meningkatkan peran kader kesehatan dan dukungan keluarga dengan melakukan pelatihan pada kader dalam untuk meningkatkan keterampilannya dalam pelayanan kesehatan pada lansia serta melakukan penyuluhan pada masyarakat untuk meningkatkan kesadaran keluarga akan pentingnya dukungan keluarga bagi lansia dalam mengikuti kegiatan yang berhubungan dengan kesehatan lanjut usia.

\section{SIMPULAN DAN SARAN}

Dari 53 orang lansia terdapat 15 orang $(28,3 \%)$ dengan pemanfaatan posyandu teratur dan 38 orang $(71,7)$ dengan pemanfaatan posyandu tidak teratur. Dari 53 orang lansia terdapat 24 orang $(45,3 \%)$ dengan dukungan keluarga sedang. 
Dari 53 orang lansia terdapat 21 orang $(39,6 \%)$ dengan peran kader kurang. Ada hubungan dukungan keluarga dengan pemanfaatan posyandu lansia lansia di wilayah kerja Puskesmas Karang Nanding Kecamatan Karang Tinggi Kabupaten Bengkulu Tengah. Ada hubungan peran kader dengan pemanfaatan posyandu lansia lansia di wilayah kerja Puskesmas Karangnanding Kecamatan Karang Tinggi Kabupaten Bengkulu Tengah. Ada hubungan kategori peran kader sedang dan dukungan keluarga dengan pemanfaatan posyandu lansia lansia di wilayah kerja Puskesmas Karang Nanding Kecamatan Karang Tinggi Kabupaten Bengkulu Tengah. Diharapkan bagi puskesmas karang nanding untuk menigkatkan pelayanan kesehatan bagi lansia khususnya posyandu lansia dengan meningkatkan peran kader kesehatan dan dukungan keluarga

\section{DAFTAR PUSTAKA}

Aminah, S. (2012). Faktor-Faktor Yang Berhubungan Dengan Pemanfaatan Posyandu Usila di Posyandu Lansia Di Kelurahan Kali Balau Kencana Kec.Sukabumi Kota B. Lampung. Jurnal Keperawatan, 10(1),64-69.

Azizah, M. (2011). Keperawatan Lanjut Usia. Yogyakarta: Graha Ilmu

Cahyani, E. (2018). Hubungan Antara Dukungan Keluarga Dengan Kunjungan Lansia Di Posyandu Lansia Kelurahan Sondakan Purwosari Surakarta. Jurnal Universitas Muhammdiyah Surakarta. Diakses pada tanggal 2 Februari 2019. http://eprints.ums.ac.id/59575/13/HASIL\%20NASKAH\%20PUBLIKASI_E RNY\%20CAHYANI.pdf.

Darmanto, J. (2015). Hubungan Kinerja Kader Posyandu Lansia Dengan Motivasi Lansia Mengunjungi Posyandu Lansia di Wilayah Kerja UPTD Kesehatan Koto Baru. Jom 2 (1) 719-728. Diakses pada tanggal 7 Februari 2019. https://media.neliti.com/media/publications/ 187518-ID-hubungan kinerjakader-posyandu-lansia-d.pdf.

Darwis. (2014). Faktor-Faktor Yang Berhubungan Dengan Kunjungan Lansia Ke Posyandu Lansia di wilayah kerja Puskesmas Rapak Mahang Kabupaten Kutai Kertanegara. JKKI,7(4), 158-167.

Demartoto, A. (2010). Pelayanan Sosial Non Panti Bagi Lansia Lansia Suatu Kajian Sosiologis. Surakarta: Sebelas Maret University Press

Depkes RI. (2008). Pedoman Pembinaan Kesehatan Lansia Bagi Petugas Kesehatan I. Jakarta: Depkes RI 
Donelan, Spetz, Auerbach \& Norman. (2018). Care Management For Older Adults: The Roles Of Nurses, Social Workers, And Physicians. Health Affairs,38 (6)

Era, P. (2016). Hubungan Antara Pengetahuan, Akses Lansia, Dan Dukungan Kader Kesehatan Dengan Keaktifan Lansia Di Posyandu Lansia Wilayah Kerja Puskesmas Mempawah Hulu. Jurnal Unnamed. Diakses pada tanggal 17 Juli 2019. http://repository.unmuhpnk.ac.id/25/.

Friedman, M. (2013). Buku Ajar Keperawatan Keluarga Riset, Teori, \& Praktik : Jakarta: EGC

Gestinarwati, A. (2016). Hubungan Dukungan Keluarga Dengan Kunjungan Lansia Ke Posyandu Aisyah di Pekon Yokyakarta Selatan wilayah kerja Puskesmas Gadingrejo Pringsewu Lampung. Jurnal Keperawatan, 7,(2),240-246 .

Hidayat, A. A. (2014). Metode penelitian keperawatan dan teknis analisis data. Jakarta : Salemba Medika

Ismawati. (2010). Posyandu dan Desa Siaga panduan untuk Bidan dan Kader. Yogyakarta : Nuha Medika

Jeurens, Turnhout \& Bakker. (2014). Increasing Family Involvement in Elderly Care. DUXU 2 (7) -403-412.

Jueriah. (2013). Dukungan Keluarga Dalam Pemanfaatan Posbindu Oleh Lansia Di Wilayah Puskesmas Haurgeulis Kabupaten Indramayu. JURNAL ILMUILMU KESEHATAN,2(2),84-89.

Kemenkes RI. (2018). Profil Kesehatan Indonesia Tahun 2017. Jakarta Kemenkes RI

Lumbantobing. (2011). Kecerdasan Pada Lansia dan Dimensia. Jakarta: FKUI.

Margiyati. (2010). Lansia dan perawatannya. Jakarta : Slemba Medika

Maryam,. S. R. (2011). Mengenal Usia Lanjut dan perawatannya. Jakarta : Salemba Medika

Melita. (2018). Faktor-Faktor Yang Berhubungan Dengan Kunjungan Lansia Ke Posbindu Lansia di wilayah kerja Puskesmas Kelurahan Bintara Kota Bekasi. $J K K I, 7(4), 158-167$.

Mubarak, W. I. (2012). Ilmu Keperawatan Komunitas. Jakarta : Slemba Medika

Nasution, Z. (2013). Pengaruh Pengetahuan, Sikap, Dukungan Keluarga dan Kader terhadap Pemanfaatan Posyandu Lanjut Usia di Wilayah Kerja Puskesmas Bandar Dolok Kecamatan Pagar Merbau Kabupaten Deli Serdang. Tesis Universitas Sumatera Utara. Diakses pada tanggal 2 Februari 2019.http://repository.usu.ac.id /handle/ 123456789/35579. 
Natalia, Y. E \& Rika, S. O. (2014). Panduan Lengkap Posyandu untuk Bidan dan Kader. Yogyakarta: Nuha Medika

Nilasari, B. (2012). Hubungan Dukungan Keluarga Dan Peran Kader Dengan Keikutsertaan Lansia Mengikuti Kegiatan Posyandu Lansia Di Posyandu Mawar Desa Tri Rahayu Kecamatan Negeri Katon Kabupaten Pesawaran. Jurnal Dunia Kesmas, 1(3).127-133.

Notoatmodjo, S. (2007). Ilmu Perilaku Kesehatan. Jakarta: Rineka Cipta

Nugroho, M. T. (2017). Hubungan Keaktifan Kader Dengan Kunjungan Lansia Di Posyandu Lansia Permadi Tlogo Suryo Malang. Nursing News, 2(1), 247255.

Nugroho, W. (2015). Buku Ajar Keperawatan Lanjut Usia. Jakarta : EGC

Nursalam. (2013). Konsep \& Penerapan Metodologi Penelitian Ilmu Keperawatan. Jakarta : Salemba medika

Panjaitan. (2017). Dukungan Keluarga Terhadap Keaktifan Lansia Dalam Mengikuti Posyandu Lansia di Puskesmas Emparu. JURNAL VOKASI KESEHATAN,4(3),78-81.

Patrisia. (2016). Faktor Peran Kader Mempengaruhi Pemanfaatan Posyandu Lansia di Desa Gantungan Makamhaji Sukoharjo. Jurnal Keperawatan, 4(2) ,7-45.

Putri. (2017). Hubungan Peran Kader Dengan Keaktifan Lansia Dalam Mengikuti Kegiatan Di Posyandu Lansia RW 1 desa kentangan wilayah kerja Puskesmas Sukomoro Kabupaten Magetan. Jurnal.BHMM,4(1),7-15.

Rahmawati. (2017). Hubungan Dukungan Sosial Keluarga Dan Kader Dengan Kunjungan Lansia Laki-Laki Ke Posyandu Lansia di wilayah kerja Puskesmas Klirong 1 Kabupaten Kebumen. Jurnal STIKES Muhammadiyah Gombong. Diakses pada tanggal 17 Juli 2019. http://elib.stikesmuhgombong.ac.id/544/1/ GALIH\%20NUR\%20RAHMAWATI\%20NIM.\%20A11300894.pdf.

Rosyid. (2012). Faktor-Faktor yang Mempengaruhi Kunjungan Lansia ke Posyandu Lansia di RW VII Kelurahan Wonokusumo Kecamatan Semampir Surabaya. Jurnal Universitas Muhammadiyah Surabaya. Diakses pada tanggal $17 \quad$ Juli 2019. http://journal.um.surabaya.ac.id/index.php/Health/article/download/9/14.

Sagitta, A, A. (2015). Hubungan Aktivitas Sosial Dengan Kualitas Hidup Lansia Di Padukuhan Karang Tengah Nogotirto Gamping Sleman Yogyakarta. Junal Universitas 'Aisyiyah Diakses pada tanggal 2 Februari 2019. http://digilib.unisayogya.ac.id/2511/. 
Santrock, (2006). Life Span Developvent: Perkembangan Masa Hidup. Jakarta: Penerbit Erlangga

Setiadi. (2012). Konsep dan Proses Keperawatan Keluarga. Yogyakarta: Graha. Ilmu

Slamet, S. (2009). Teori-Teori Psikologi Sosial. Bandung: Refika Aditama

Smeltzer \& Bare. (2012). Buku Ajar Keperawatan Medikal Bedah. Jakarta: EGC

Suardiman, S. P. (2011). Psikologi Usia Lanjut. Yogyakarta: Gadjah Mada Press

Sudarmi. (2014). Faktor-Faktor Yang Berhubungan Dengan Pemanfaatan Posyandu Lansia Di Wilayah Kerja Puskesmas Pesisir Tengah Kabupaten Pesisir Barat Provinsi Lampung. Jurnal Kesehatan.7(2),8-14

Sulistyorini. (2010). Posyandu Dan Desa Siaga. Yogyakarta: Nuha Medika

Ughniyatul, M. (2015). Hubungan Peran Kader dengan Keaktifan Kunjungan Posyandu Lansia di Wilayah Kerja Puskesmas Godean II. Jurnal Universitas Gadjah Mada. Diakses pada tanggal 7 Februari 2019. http://etd.repository.ugm.ac.lid/index. php?mod=penelitian_detail\&sub=PenelitianDetail\&act=view\&typ=html\&b uku_id=97510\&obyek_id=4.

Wahono, H. (2010). Analisis Faktor-Faktor Yang Mempengaruhi Pemanfaatan Posyandu Lansia Di Gantungan Makamhaji. Jurnal Universitas Muhammadiyah Surakarta. Diakses pada tanggal 7 Februari 2019. http://eprints.ums.ac.id/9520/1/ J210080010.pdf.

Zakir, M. (2014). Faktor-Faktor Yang Behubungan Dengan Pemanfaatan Posyandu Lansia Kencana di Wilayah Kerja Puskesmas Sukabumi Bandar Lampung. Jurnal Keperawatan,10(1),64-69.

Zulkifli. (2010). Posyandu dan Kader Kesehatan. Medan : FKM-USU 